\title{
COMO TRABALHAR O TEXTO LITERÁRIO LEVANDO EM CONSIDERAÇÃO SUAS ESPECIFICIDADES
}

\author{
Karina CERIBELLI ROY, Doutoranda - USP ${ }^{1}$
}

RESUMO: neste artigo discuto a forma de trabalhar o texto literário em um curso de Francês Língua Estrangeira. Primeiro trato da definição do texto literário, quais são suas características. $O$ texto literário possui espeficidades que não devem deixar de ser levadas em consideração quando trabalhado na sala de aula. Em seguida analiso duas atividades propostas nos livros didáticos Reflets Méthode de français 3 (2002) e Le Nouveau sans Frontière 4 - Méthode de français (1993) sobre trechos do livro India Song (1975) e L'Amant (1984) de Marguerite Duras. O objetivo foi verificar se as propostas pedagógicas respeitavam as características do texto literário que segundo Amor Séoud (1997) são a polissemia, o prazer e a interculturalidade. No primeiro método os didáticos não levaram em consideração as características do texto literário ao propor perguntas de compreensão escrita, enquanto o segundo método, apesar de pouco profundo, faz perguntas pertinentes levando em conta as particularidades do texto literário. Para terminar proponho sugestões para utilizar poemas com os alunos iniciantes, além de chamar a atenção para que o professor tenha um projeto de leitura antes de iniciar suas aulas.

PALAVRAS-CHAVE: Ensino; literatura; Francês Língua Estrangeira; polissemia; prazer do texto; interculturalidade.

ABSTRACT: in this paper I discuss a way of working the literary text in a French as a Foreign Language course. Firstly, I work the definition of literary text and its characteristics. The literary text has specific characteristics that cannot be ignored when it is used in the classroom. After that, I analyze two activities proposed by the didactic books Reflets Méthode de français 3 (2002) and Le Nouveau sans Frontière 4 Méthode de français (1993) about passages of the book India Song (1975) and L'Amant (1984) by Marguerite Duras. The objective was to verify whether the pedagogic proposals respected the characteristics of the literary text that, according to Amor Séoud (1997), are polissemy, pleasure and interculturality. In the first method, the authors did not consider the characteristics of the literary text when they proposed reading comprehension questions, while the second method, even though not quite deep, makes pertinent questions considering the characteristics of the literary text. Finally, I make suggestions about the utilization of poems with initial students and I also show to professors the importance of having a reading project before the beginning of classes.

KEY WORDS: teaching, literature, French Foreign Language, polissemy, pleasure of text, interculturality.

\footnotetext{
${ }^{1}$ Doutoranda do Programa de Pós-Graduação em Estudos Linguísticos, Literários e Tradutológicos em Francês Universidade de São Paulo (USP). Faculdade de Filosofia, Letras e Ciências Humanas - São Paulo - SP, - Brasil. 05508-900.
} 


\section{INTRODUÇÃO}

Este artigo tem como objetivo refletir sobre o ensino da literatura no curso de graduação de Francês Língua Estrangeira. O livro Pour une didactique de la litttérature de Amor Séoud (1997) serve de base teórica para o nosso artigo. A partir da leitura desse livro serão apreendidas as possíveis leituras que podem ser feitas do texto literário no contexto escolar e que envolvem a polissemia, o prazer e a interculturalidade.

Em um primeiro momento vamos tratar de definir o que é um texto literário, quais são suas características, para em um segundo momento analisar duas atividades pedagógicas propostas nos livros didáticos Reflets 3 e Le Nouveau sans Frontières 4 sobre trechos de textos literários de Marguerite Duras. Nossa ideia é verificar se as propostas pedagógicas respeitam as características do texto literário.

Segundo Pietraróia (1997, p. 24), “A base da metodologia tradicional era o próprio objetivo da aprendizagem: aprender uma língua estrangeira para poder compreendê-la, falá-la, mas, sobretudo, para ter acesso a uma cultura de prestígio.” Para isso eram usados textos literários dos escritores mais importantes da literatura francesa. Conforme afirma Pietraróia, saímos de uma época de onipotência do texto literário para um período de ausência, por ser hoje a comunicação prática a maior preocupação dos métodos didáticos. Portanto o texto literário foi pouco a pouco marginalizado por não fazer parte do quotidiano do aluno que precisa aprender a língua estrangeira para se comunicar.

\section{A PLURALIDADE DO TEXTO}

Segundo Séoud (1997, p.45) "temos o hábito de opor o discurso literário ao discurso quotidiano", sendo que a característica lingüística principal do primeiro é a polissemia, enquanto o segundo visa, em geral, um único sentido, já que o seu objetivo principal é a comunicação. No entanto, sabemos que mesmo o discurso quotidiano também possui vários sentidos, pois nem sempre o ouvinte entende a mensagem que o falante pretendia comunicar; ou então o falante transmite uma mensagem, mas, na verdade, desejava comunicar outra. Sendo assim, a diferença é que o discurso literário visa à pluralidade de sentidos e o discurso quotidiano visa, principalmente, à comunicação. 
Roland Barthes (1964, p. 14) afirma que a literatura é a expressão secundária de uma mensagem original, e que a linguagem escrita torna-se obra quando ela pode variar, de certa forma, essa mensagem primária. Caso o escritor publicasse a mensagem original, tal qual ele a concebeu, sem que houvesse uma lapidação da linguagem, ela seria despojada de afeto, correria o risco de não despertar a emoção no leitor, e provavelmente teria um caráter banal. Assim, o escritor deve escolher uma forma de comunicação indireta, cheia de singularidades, onde a linguagem seja bem trabalhada para transmitir a primeira mensagem que lhe serviu de inspiração, em uma forma variável, ou seja, disfarçada de mensagem secundária. Portanto, o texto literário é nesse sentido rico para ser trabalhado na sala de aula por despertar a emoção do leitor e permitir múltiplas leituras.

Na conferência de abertura do XI Encontro Regional da Abralic, no dia 23 de julho de 2007, intitulada "O Ensino da Literatura Hoje”, Leyla Perrone-Moisés afirma que a grande obra tem inúmeras portas de entrada, ou seja, tem diversas possibilidades de interpretação, sendo que cabe ao professor escolher a porta de entrada que melhor lhe convém para trabalhar o texto literário na sala de aula.

Para Séoud (1997), o professor deve desenvolver na sala de aula métodos de ensino que trabalhem a pluralidade do texto literário. Ele critica as escolas francesas por terem o hábito de fazer um exercício chamado "explicação de texto" nas aulas de literatura. Essa prática é banida pelo autor e por outros teóricos por dar ao texto uma única voz:

A primeira grande orientação de toda nova didática nos parece, no entanto, ir em direção a "desintegração" deste exercício acadêmico, em FLM (Francês língua materna) como em FLE (Francês língua estrangeira). Não é possível sabendo agora do caráter polissêmico essencial dos discursos literários, continuar a fazer o contrário do que se deve ser feito, reduzindo esses discursos, por qualquer que seja o meio, à univocidade ${ }^{2}$. (SÉOUD, 1997, p. 102) (Tradução é nossa) ${ }^{3}$

Segundo a citação acima a nova orientação didática deve-se privar desse tipo de exercício por reduzir a leitura do texto a um único sentido. Séoud (1997) mostra que as novas práticas pedagógicas supõem o desenvolvimento da pluralidade e da capacidade de construção do sentido, onde o aluno elabora com o professor o sentido do texto. $\mathrm{O}$

\footnotetext{
2 La première grande orientation de toute didactique nouvelle nous semble pourtant devoir aller vers la "désintégration" de cet exercice académique, en F.L.M. comme en F.L.E. Il n'est pas possible, sachant maintenant le caractère polysémique essentiel des discours littéraires, de continuer à faire le contraire de ce qui doit être fait, en ramenant ces discours, par quelque moyen que ce soit, à l'univocité. (SÉOUD, 1997, 102)

${ }^{3}$ Todas as traduções são do autor deste artigo.
} 
professor não é mais o único detentor do saber que transmite para o aluno o conhecimento. $\mathrm{O}$ aluno constrói o sentido auxiliado pelo professor e pelos colegas de classe. Portanto a nova prática deve criar um ambiente propício ao aluno para que ele construa o sentido do texto ao interagir com o mesmo e perceba a multiplicidade de vozes.

Por outro lado, já que o objetivo dessa prática é, finalmente, sensibilizar o aluno à polissemia dos discursos, a sua literariedade, ter-se-á sem dúvida interesse em iniciar a aprendizagem por textos nos quais essa seja a mais facilmente desvendável. Opor-se-á assim a uma tendência habitual que privilegia, nesses inícios, o emprego desses textos os mais "acessíveis", ou os mais legíveis, pois na perspectiva onde nós nos situamos, a dificuldade pedagógica pode nascer paradoxalmente do excesso de legibilidade4. (SÉOUD, 1997, p. 107)

Como a "prática de texto" tem como objetivo sensibilizar o aluno ao discurso polissêmico do texto literário, Séoud sugere que o professor comece o curso com textos que possam ilustrar essa pluralidade de sentido. Essa sugestão é contrária à prática corriqueira, na qual o professor tem o hábito de trazer, no início do curso, textos que não provoquem dificuldade de interpretação: em geral utilizam-se textos elaborados para os manuais didáticos, os chamados textos fabricados, que se opõem aos textos autênticos. Esse procedimento dificulta o trabalho do próprio professor, pois o excesso de legibilidade não permite mostrar ao aluno a polissemia do texto: por ser fácil demais, haverá apenas um sentido, simples de ser identificado.

Séoud (1997, p.108) cita uma exploração pedagógica de textos narrativos proposta por Jean-Claude Gagnon que pode ser feita para trabalhar textos literários: “Trata-se, então, de ajudar os alunos a se colocar em situação de leitura propondo-lhes,

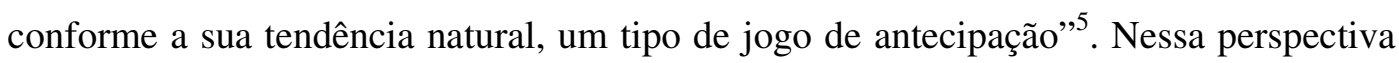
os alunos serão conduzidos a se colocarem na posição de leitor. À medida que o aluno lê um trecho da história, ele deverá fazer hipóteses sobre a sua continuação e, conforme ele avança na leitura, ele mesmo verificará se as suas formulações coincidem ou não com a história, modificando-as ao longo da sua leitura. Para isso é preciso que o aluno tenha acesso a partes do texto e não ao texto integral. Essa técnica chama-se jogo de

\footnotetext{
${ }^{4}$ D'autre part, puisque l'objectif de cette pratique est, finalement de sensibiliser l'apprenant à la polysémie des discours, à leur littérarité, on aura sans doute intérêt à commencer au début des cursus par des textes où celle-ci est la plus facilement décelable. On s'opposera ainsi à une tendance habituelle qui privilégie, dans ces débuts, le recours aux textes les plus "accessibles", ou les plus "lisibles", car dans la perspective où nous nous plaçons, la difficulté pédagogique peut naître paradoxalement de l'excès de lisibilité. (SÉOUD, 1997, p. 107)

5 "Il s'agit alors d'aider les élèves à se mettre en situation de lecture en leur proposant, conformément à leur tendance naturelle, une sorte de jeu d'anticipation. " (1997, p.108)
} 
antecipação: o objetivo é despertar no aluno a consciência do processo de construção do sentido. Aos poucos, lendo o livro e discutindo com os colegas, ele perceberá como a história é construída.

Essa orientação didática proposta por Jean-Claude Gagnon está preocupada com a interação entre o texto e o aluno. O objetivo do professor é despertar no aluno o prazer do texto, levando-o a construir o sentido segundo sua experiência pessoal e, apenas no final do curso de leitura, o professor abordará a vida do autor, as obras escritas e o contexto histórico. A vantagem dessa proposta de leitura é aproximar o aluno do texto, como ele faria sozinho ao comprar um livro na livraria ou ao pegar emprestado em uma biblioteca. O leitor quando inicia uma leitura, em geral, não procura saber sobre a vida de quem escreveu o livro, em que época foi escrito e qual o seu contexto histórico. Portanto, não há necessidade do professor introduzir todas essas questões que envolvem a obra antes de propor a sua leitura. Esses conhecimentos em torno do livro contribuiriam para uma receptividade negativa por parte do aluno, por entender que para se ler uma obra é preciso antes fazer uma pesquisa.

Jean-Pierre Cuq e Isabelle Gruca (2005, p. 421) também propõem uma atividade de pré-leitura. Segundo os pesquisadores o livro trabalhado na sala de aula deveria ser tratado da mesma maneira que tratamos o livro escolhido na livraria. É preciso, em primeiro lugar, interrogar o título, observar a apresentação iconográfica, sua fisionomia tipográfica, para perceber sua estrutura, seu tipo de discurso, o gênero o qual ele pertence; confrontar essas informações recolhidas na capa e na contra capa, no prefácio, etc. Quando esses componentes não parecerem apropriados, a etapa da préleitura pode se apoiar em atividades lúdicas, a fim de tornar possível a antecipação do conteúdo do texto ou facilitar a leitura. Todas essas propostas desejam despertar no aluno o interesse pela leitura e não, ao contrário, a sua rejeição por acreditar que ler é maçante e desgostoso.

\section{O prazer do texto}

Ler é uma atividade considerada prazerosa, no entanto muitos recusam desfrutar esse prazer. "Um francês em cada dois, parece, não lê; metade da França está privada se priva do prazer do texto."6 (BARTHES, 1973, p.63) A questão colocada por Séoud

\footnotetext{
6 "Un français sur deux, paraît-il, ne lit pas; la moitié de la France est privée - se prive du plaisir du texte." (BARTHES, 1973, p.63)
} 
diante desse quadro, onde apenas $50 \%$ dos franceses lêem, é: para que serve formar críticos ou aprendizes de crítica literária, quando os alunos não lêem? Sabe-se que eles lêem livros de análise crítica das obras, sem nunca terem lido as obras; alguns são capazes até de dissertar sobre as mesmas e obter bons resultados nos exames. A realidade brasileira é ainda mais complicada, pois segundo Ubiratan Brasil (2010), à uma pesquisa realizada pela Fecomércio-RJ, a "maioria das pessoas (60\%) respondeu não ter o costume de ler, enquanto (22\%) confessam não gostar: assistir à TV é o passatempo preferido dos brasileiros." Assim sendo, em uma sociedade que não tem o hábito da leitura, onde o livro não é visto como uma atividade prazerosa, despertar o gosto da leitura torna-se um desafio para as escolas brasileiras. O professor de francês língua estrangeira terá que enfrentar duas dificuldades: a antipatia pela leitura em língua materna e a dificuldade de ler em língua estrangeira. Por esse motivo o professor brasileiro deve desenvolver não apenas estratégias de leitura em língua estrangeira, mas também convencer seus alunos de que ler é prazeroso.

Até há pouco tempo, na França, a escola não se preocupava em motivar o prazer da leitura, havia um conteúdo que tinha que ser dado e os alunos deviam ler o que era pedido. Entretanto a orientação pedagógica mudou:

Essa perspectiva é, aliás, didaticamente interessante por estar acontecendo hoje, em didática de uma maneira geral, em F.L.M. como em F.L.E., uma passagem da centralização nos métodos (de ensino) a uma centralização no aluno (resultando o interesse pelo aprendizado). De fato é evidente que, no campo do ensino de literatura, o reconhecimento do prazer como finalidade significa o reconhecimento do lugar do sujeito dentro desse mesmo campo7. (SÉOUD, 1997, p. 118)

Hoje se constata que a orientação didática coloca o aluno no centro do ensino. Para que isso ocorra no ensino de literatura, é preciso reconhecer o prazer como finalidade, desta forma o aluno é colocado no centro desse ensino. Cabe ao professor ter como objetivo essencial despertar o interesse pela leitura. Séoud (1997, p.118) fala de motivação à leitura, de provocação ou desenvolvimento do desejo de ler.

Segundo os educadores Séoud (1997) e Pennac (1992a) há uma tendência de se falar sobre o autor, sobre as obras, sobre o momento histórico em que foi escrito o livro,

\footnotetext{
7 “Cette perspective est d'ailleurs didactiquement d'autant plus intéressante qu' il se produit aujourd'hui, en didactique d'une façon générale, en F.L.M. comme en F.L.E., un passage de la centration sur les méthodes (de l'enseignement) à une centration sur l'apprenant (résultant de l'intérêt pour l'apprentissage). Or il est évident que, dans le champ de l'enseignement littéraire, la reconnaissance du plaisir comme finalité signifie la reconnaissance de la place du sujet à l'intérieur de ce même champ. " (SÉOUD, 1997, p. 118)
} 
esquecendo-se de que o centro do ensino deve ser o aluno e o texto. Portanto, em primeiro lugar, deve-se tratar de como o aluno entende a obra, para em um último momento falar acerca da obra. Essa preocupação em tratar do assunto que está fora do texto leva o aluno a rejeitá-lo, não lhe despertando o prazer pela leitura, ao contrário, desestimulando-o. Pennac (1992a, p.140) fala que "a única condição para a reconciliação com a leitura: [é] não pedir nada em troca. Absolutamente nada. Não elevar nenhuma muralha de conhecimentos preliminares a cerca do livro" ${ }^{\text {}}$. Portanto, a reconciliação com a leitura só será possível se o professor não tratar de assuntos a respeito do texto que desencorajem a leitura, e acabam colocando o texto em segundo plano. Isso depende de cada turma, estamos falando daquelas que tem aversão à leitura, para esse tipo de grupo o importante é não associar o conhecimento prévio a compreensão de uma obra, pois o aluno acaba achando que para ler ele precisa antes conhecer muito bem o autor, o contexto histórico e a obra, sendo que ele precisa mesmo é ler o livro sugerido.

Daniel Pennac (1992b) conta como a experiência de ler em voz alta romances para seus alunos na sala de aula serviu para reconciliar o aluno com o livro. Ele tinha descoberto, ao conversar com os pais dos alunos, que eles paravam de ler à noite para seus filhos quando os mesmos entravam na escola. Essa ruptura quebra o valor afetivo que o aluno tinha com o livro, pois se estabelece uma trindade entre "o livro, a mãe e o filho que se identifica com os heróis, toda essa plenitude, esse sentimento de totalidade absoluta, todos os ingredientes são dados ali a criança para lançar-se no livro e recriar sozinha a magia." 9 (PENNAC, 1992b, p.48) Por isso ele aconselha aos pais a continuarem a ler para seus filhos, mesmo quando eles já estão na escola, para que os filhos não deixem de ter essa relação afetiva com o livro; caso contrário, o professor terá que reconquistar essa afetividade em um ambiente artificial, que é a escola. "A aprendizagem na escola e o presente da leitura à noite, há aí duas linhas que convergem e que levam devagarzinho em direção ao livro." ${ }^{10}$ (PENNAC, 1992b, p.48)

\section{O intercultural}

\footnotetext{
8 “ Une seule condition à cette réconciliation avec la lecture : ne rien demander en échange. Absolument rien. N'élever aucun rempart de connaissances préliminaires autour du livre.’(PENNAC, 1992a, p.140)

9 "Cette espèce de trinité entre le livre, la maman et le gosse qui s'identifie aux héros, toute cette plénitude, ce sentiment de totalité absolue, tous les ingrédients sont donnés là à l'enfant pour foncer vers le livre et récréer tout seul la magie." (Id.,1992b, p.48)

10 "L'apprentissage à l'école et le cadeau de la lecture du soir, il y a là deux lignes qui convergent et qui l'emmènent tout doucement vers le livre." (Ibid, 48)
} 
Séoud (1997) afirma que a literatura tem sua função social na medida em que ela é representativa das referências culturais de uma comunidade. As pessoas integram-se ou identificam-se graças à literatura. A literatura exerce um papel preponderante na sociedade por representar os costumes, os pensamentos, a filosofia da população de uma determinada época. No entanto é importante lembrar que por mais realista que o texto seja, para Séoud, ele nunca será a realidade, mas será a representação da realidade vista por um indivíduo em um dado momento, em um dado lugar. Essa representação da realidade está plena de referências culturais e históricas. Portanto o leitor lê o que o olhar do outro mostra. Séoud (1997, p. 138) diz que "a leitura seria, então, somente um olhar sobre (através) um outro olhar" ${ }^{\prime 1}$. Entretanto, quando se trata de literatura, essa leitura feita através do olhar do leitor é múltipla, por se tratar de textos polissêmicos. Consequentemente na sala de aula haverá um processo de cruzamento de olhares, ainda mais complexo, por haver vários leitores de culturas diferentes. Portanto várias leituras serão possíveis de um mesmo texto, escrito por uma pessoa que tem sua representação própria da realidade.

Sabe-se que o "intercultural" é uma nova percepção que deve ser formada, desenvolvida. A pergunta que se faz então é como abordá-lo? Séoud (1997, p. 139) diz que a resposta ou uma parte dessa resposta está no próprio problema: "da mesma forma que podemos ver o Outro somente através de nós mesmos, só nos vemos através do Outro". Sendo assim, a confrontação com o outro se torna um elemento indispensável do conhecimento e consequentemente do aprendizado. Portanto a comparação é a primeira etapa do processo.

Para Marc Lits (1994, p. 27) os alunos não percebem o seu próprio ambiente cultural sem fazer a comparação, logo, é preciso descobrir a cultura do outro para poder perceber as suas particularidades culturais.

Segundo Séoud, falar do outro é, sobretudo, falar de você mesmo. Isso explica a razão por que a didática do intercultural supõe que o professor deva deixar o aluno falar. Segundo Luc Collès (1994, p. 39) é preciso, antes de tudo, deixar o aluno julgar por ele mesmo em função de seus próprios valores culturais. Henri Besse (1993, p. 47) vai mais além, propondo ao professor dar aos alunos informações relativas à cultura estrangeira que possam gerar problemas, a fim de provocar neles certo choque que mostre a

\footnotetext{
11 "la lecture ne serait donc qu'un regard sur (ou travers) un autre regard." (p. 138)
} 
distância da cultura estrangeira. É o distanciamento em relação à cultura estrangeira que deve levar o aluno a perceber que ele pertence à sua cultura. Desta maneira ele poderá confrontar as duas culturas e notar o que cada uma tem de positivo e que pode lhe servir para abrir seu horizonte como ser humano.

Para Séoud (1997) o indivíduo deve acabar por se colocar em questão, e se tornar o próprio objeto de análise. Isso só é possível graças à confrontação e a comparação com outros indivíduos e com outras culturas. Portanto cabe ao professor de literatura em língua estrangeira despertar no aluno uma reflexão sobre a sua própria cultura, usando a comparação como ferramenta para esse processo.

No segundo momento do artigo, analisaremos a abordagem didática de alguns textos literários de Marguerite Duras nos livros didáticos. Analisaremos se os aspectos apontados acima foram levados em consideração.

Para análise das atividades didáticas escolhidas demos preferência aos textos da Marguerite Duras, cuja obra se insere no perfil dos autores sugeridos em Pour une didactique de la littérature de Séoud (1997), para serem trabalhados na sala de aula, pois além de ser uma escritora marcante da literatura do século $\mathrm{XX}$, ela se presta à análise que enfoca o prazer, o estudo da polissemia e o intercultural.

\section{O método didático dá conta da especificidade do texto literário?}

Foram escolhidos dois métodos de F.L.E. Reflets 3 e Le Nouveau sans Frontières 4. Ambos possuem propostas didáticas com textos de Marguerite Duras.

O método Reflets 3 foi escrito por Catherine Dollez e Sylvie Pons, publicado em 2001. Esse método é composto de 3 livros, cada um possui um nível com 12 unidades, chamadas de dossiê. Cada dossiê do Reflets 3 é dividido em 8 partes: "Descoberta", "Informações", "Gramática", "Vocabulário", "Uma página da história”, "Oral", "Escrita", "Saber-fazer"12. O público visado é adolescente e adulto. Cada nível comporta de 120 a 150 horas de aprendizagem de francês língua estrangeira.

Analisaremos a atividade pedagógica proposta no volume 3 do método Reflets, do dossiê 1 chamado "Viver junto" 13 da parte "Escrita". Os autores escolheram trabalhar três trechos de romances: L'Amant da Marguerite Duras, La princesse de Clèves da Madame de La Fayette e Passion simple da Annie Ernaux. (ver anexo)

\footnotetext{
12 "Découverte", "Infos", "Grammaire”, "Vocabulaire", “Une page d'histoire", "Oral”, "Écrit", "Savoir-faire".

13 "Vivre ensemble"
} 
O objetivo desta parte chamada "Escrita", segundo os autores, é "produzir um texto que exprima os sentimentos (a partir da matriz de uma narrativa literária.) ${ }^{14}$ (DOLLEZ; PONS, 2002, p. 7) A frase que introduz o exercício da página 17 é: "Vocês irão utilizar a matriz de uma narrativa literária para relatar uma relação afetiva."15 Notase nesses dois comentários a preocupação demasiada com o contexto de produção escrita e não com a sensibilização à leitura. Ao analisar a atividade, notamos que de fato os textos literários servem de pretexto para uma produção escrita, não havendo uma proposta de leitura.

O primeiro exercício pede ao aluno que atribua aos três romances a data de publicação. Antes desta pergunta, os autores poderiam trabalhar a capa ou o título dos livros para fazerem o "jogo de antecipação" "16 que permitiria levantar hipóteses sobre o que aconteceria na história. Portanto, não deveria se falar no início da página em uma "relação afetiva" ${ }^{17}$, pois isso revela aos alunos o assunto que será abordado, sem deixálos descobrir por eles mesmos o tema dos trechos escolhidos. Por outro lado o fato de anunciar que o aluno terá que "relatar uma relação afetiva" prioriza a atividade de escrever e não sensibiliza ao prazer da leitura.

Outro aspecto que pode ser notado nas perguntas sobre o texto 1 é que não há referência ao intercultural. Poderia ter sido proposta uma atividade sobre a foto do filme $O$ Amante de Jean- Jacques Annaud que aparece ao lado do trecho do texto de Marguerite Duras. Muitos alunos podem já ter visto o filme e a partir da memória deles, é possível provocar um debate sobre esse assunto. A foto poderia servir de pretexto para abordar o tema da colonização, da relação amorosa de um chinês mais velho com uma menina branca de quinze anos. Em uma perspectiva intercultural levar-se-ia os alunos a comparar as relações amorosas inter-raciais em seu país com a situação apresentada no livro L'Amant.

O mesmo ocorre com relação ao romance La Princesse de Clèves, pois não há nenhuma pergunta que possa discutir a postura da Madame de Clèves que, mesmo apaixonada pelo Monsieur de Nemours, se mantém fiel ao marido morto. Poderia ter sido proposta uma atividade de discussão que fizesse uma comparação com os dias de hoje, através de perguntas como: será que uma mulher deixaria de ficar com o homem que ama, depois da morte do marido? Por que vocês acham que isso é possível no

\footnotetext{
14 "Produire un texte exprimant des sentiments (à partir de la matrice d'un récit littéraire)."

15 "Vous allez utiliser la matrice d'un récit littéraire pour relater une relation affective."

16 "un jeu d'anticipation"

17 "relation affective"
} 
romance? Por que a Madame de Clèves não recebe o Monsieur Nemours depois da morte do marido? O que isso significa para o padrão da época? O que vocês acham desse comportamento da mulher do século XVII? O que mudou?

As questões sobre os trechos dos três romances são superficiais, não abordam a característica principal do texto literário que é a polissemia. Apenas a pergunta 16 poderia levar a trabalhar a polissemia quando, sobre o texto 3, se pergunta: "Por que o amante não intervém?"18 No livro do professor a resposta esperada é : "O amante é excluído da narrativa, é uma paixão "simples" e não dupla, recíproca."19 (DOLLEZ; PONS, 2002, p. 23) Dificilmente o aluno que não leu esse romance poderá chegar a essa resposta apenas com a leitura do trecho proposto. Acredita-se que haverá várias interpretações. Alguns alunos poderão pensar que o amante morreu, ou que os amantes brigaram, e nunca mais se viram, etc. Se o título "Paixão Simples"20 fosse discutido, isso ajudaria provavelmente a levantar outras hipóteses, dentro das quais, talvez, o aluno chegaria a resposta mais próxima do conteúdo do livro. Alguns alunos poderiam pensar que este título trata de uma história de amor simples com final feliz; outros poderiam ir mais além, percebendo o jogo de palavras Paixão Simples e "passé simple", o que leva a pensar que se trata de uma história de amor acontecida no passado; por último, poderiam chegar à resposta que se trata de uma história de amor simples onde apenas uma pessoa amou, e não dupla, onde os dois se amaram.

A terceira atividade propõe uma preparação à produção. Ela ignora completamente os dois primeiros textos e pede ao aluno que se atenha apenas ao texto 3 . Fica claro aqui que os textos serviram de pretexto para a atividade de expressão escrita. $\mathrm{Na}$ verdade, os autores poderiam ter suprimido os outros dois trechos dos romances e aprofundado mais a atividade de leitura do terceiro texto. A impressão que se tem da maneira como a atividade foi elaborada é que o aluno faz um sobrevôo do texto, mas não entra no texto propriamente dito. $\mathrm{O}$ aprofundamento da leitura permitiria ao aluno entrar em contato com um novo universo criado pelo autor. A partir do ponto de vista do outro o aluno, guiado pelo professor, poderia refletir sobre os seus próprios valores ao compará-los com os do autor. O conhecimento que a leitura de um livro proporciona ao leitor, não poderia ser atingido por aqueles que apenas sobrevoam o texto, sem de fato entendê-lo e discuti-lo:

\footnotetext{
18 "Pourquoi l'amant n'intervient-il pas?"

19 "L'amant est exclu du récit, c'est une passion "simple" et non double, réciproque." (DOLLEZ ; PONS, 2002, p. 20 "Passion Simple"
} 
Pela arte somente nós podemos sair de nós, saber o que vê um outro deste universo que não é o mesmo que o nosso, e cujas paisagens nos ficariam tão desconhecidas que aquelas que pode haver na lua. Tratase, graças à literatura, de ver o mundo com os olhos de um outro, de ter acesso ao mundo do outro, por isso de compreender o outro, de ter acesso a ele ou a ela. A literatura é conhecimento, não recuo, separação ou segredo21. (COMPAGNON, 2010, p.50)

O método Le Nouveau sans Frontière, publicado em 1993, é composto por 4 livros cada um contém um nível. O quarto volume da coleção foi escrito por Jacky Girardet e visa um público de adolescentes e adultos que tenham tido 400 horas de ensino de francês língua estrangeira. O quarto volume contém 12 unidades chamadas de dossiê, cada um contém as seguintes partes: "Idéias", "Literatura", “A cena e a tela", "As artes", "Voz", "Ferramentas para expressão"22.

No método Le Nouveau sans Frontière 4 o trecho de India Song de Marguerite Duras aparece na parte "A Cena e a Tela" 23 que propõe trabalhar trechos de peças de teatro ou de roteiros de filmes. O autor propõe abordar o problema da representação, a análise de imagem e a adaptação cinematográfica das obras narrativas. (ver anexo)

A atividade pedagógica inicia com o título: "A Narrativa Polifônica"24. É interessante esse título por abrir a possibilidade de discutir o que é uma narrativa polifônica, preparando o aluno para o texto durassiano que pode causar estranhamento, pois em India Song Marguerite Duras conta uma história através de várias vozes não identificadas.

Na primeira atividade pede-se que sejam tirados do texto elementos que façam referência à história da mendiga, do Vice-cônsul e de Michael Richardson. A partir dessa seleção de informações o aluno deve resumir o que ele entendeu da história, do cenário e do ambiente. A proposta pedagógica é interessante, por levar o aluno a entrar em contato com o texto, no entanto se o aluno ler o resumo que vem antes do texto, ele poderá responder a primeira parte sem precisar ler o texto em si. Parece que o autor subestima a capacidade do aluno em construir apenas a partir do texto de Marguerite Duras suas hipóteses sobre a história, os personagens, o cenário e etc.

\footnotetext{
${ }^{21}$ Par l'art seulement nous pouvons sortir de nous, savoir ce que voit un autre de cet univers qui n'est pas le même que le nôtre, et dont les paysages nous seraient restés aussi inconnus que ceux qu'il peut y avoir dans la lune. Il s'agit, grace à la littérature, de voir le monde avec les yeux d'un autre, d'avoir accès au monde de l'autre, donc de comprendre l'autre, d'accéder à lui ou à elle. La littérature est connaissance, non pas repli, séparation ou secret. (COMPAGNON, 2010, p.50)

22 "Idées", "Littérature", "La scène et l'écran", “Les arts", "Voix”, "Outils pour l'expression”.

23 "La Scène et l'Écran"

24 "Le Récit Polyphonique"
} 
O segundo exercício aborda a "escrita mágica" de Marguerite Duras. Essa proposta novamente é interessante, pois pede ao aluno que compare as passagens descritivas, narrativas e os diálogos de India Song com seus equivalentes na literatura clássica. Em seguida pede que mostre a especificidade da narrativa, da descrição e do diálogo de Marguerite Duras. Essa atividade dá bastante ênfase à observação do estilo durassiano a fim de preparar o aluno para o último exercício de criatividade onde deve escrever uma história poética utilizando uma das técnicas de Marguerite Duras: uma polifonia de vozes ou fragmentos de conversas entre as testemunhas dessa história.

Novamente pode-se perceber que a finalidade da proposta pedagógica era fazer com que o aluno escrevesse. No entanto a diferença em relação à atividade do Reflets 3 é que nessa houve um trabalho mais profundo em descobrir as técnicas de escrita da Marguerite Duras. Entretanto falta ainda um trabalho mais minucioso com o texto, que explore a polissemia. Seria preciso fazer um recorte do trecho proposto, a fim de analisá-lo com uma lupa e de identificar as características polissêmicas, afinal o aluno que chegou ao $4^{\circ}$. livro Le Nouveau sans Frontière já estudou 400 horas de francês língua estrangeira, portanto tem a capacidade de se aprofundar em sua leitura. Com o texto sugerido pelo método, o professor poderia recortar uma parte e pedir que o aluno faça a análise de um parágrafo que se abre para várias interpretações, como o seguinte exemplo:

\section{Teтро}

- Não existiria em cada um de nós...como dizer? uma chance sobre mil de ser como ele a ... enfim... (parada) faço a pergunta... é tudo... ${ }^{25}$

Sem resposta. Silêncio.

\footnotetext{
25 Temps.

- Est-ce qu'il n'y aurait pas en chacun de nous... comment dire? une chance sur mille d'être comme lui à... enfin...(arrêt) je pose la question... c'est tout...
} 
(DURAS, 1973, p.67) ${ }^{26}$ (Tradução nossa)

No trecho anterior a esta citação, as vozes estão falando sobre a infância do vice-cônsul, filho único, cujo pai era um banqueiro de Neuilly, e cuja mãe teria abandonado o pai. Em seguida o diálogo abre para uma conversa cheia de reticências que nos permite várias leituras. Uma delas é que as vozes sugerem que a loucura do vice-cônsul tenha sido causada na infância quando mãe abandou-os. Uma das vozes pergunta: não existiria uma chance sobre mil de sermos como ele... ? Em uma sala com vinte alunos, poderá haver várias leituras desse mesmo trecho.

Outro trecho de India Song poderia ter sido escolhido, onde a polissemia do texto durassiano seria mais evidente, como nos momentos em que as histórias da mendiga e da Anne Marie Stretter se confundem, e que o uso dos pronomes não permite distinguir de qual das duas está se falando.

Nota-se que os textos literários propostos na atividade pedagógica do método Refltes 3 servem apenas de pretexto para a atividade escrita. Entretanto, no caso do método Le Nouveau sans Frontière 4 a atividade proposta é mais interessante, pois se preocupa em levar o aluno a perceber a especificidade da escrita da Marguerite Duras. No entanto, é pena que seja preciso chegar ao nível 4 de língua para ter um trabalho motivador com textos literários.

Vimos que conforme Séoud (1997) é possível desde o início da aprendizagem da língua estrangeira abordar textos literários, não é preciso esperar 450 horas de curso. Henri Besse (1974, p.70) sugere que se trabalhe com poemas modernos ou contemporâneos por solicitar menos conhecimento prévio de regras de versificação que os poemas clássicos. Pode-se começar com poemas contemporâneos por serem ótimos exemplos de textos polissêmicos. Um exemplo disso é o poema de Blaise Cendrars.

\section{Você é mais bela que o céu o mar}

Quando você ama é preciso partir

Deixe sua mulher deixe seu filho

Deixe seu amigo deixe sua amiga

Deixe sua amante deixe seu amante

Quando você ama é preciso partir ${ }^{27}$

\footnotetext{
${ }^{26}$ Esse texto proposto pelo método Le Nouveau sans Frontière 4 foi tirado do livro India Song de Marguerite Duras. Procuramos deixar o mesmo layout que se encontra no livro de Marguerite Duras, pois para caber no método houve modificações.

Tu es plus belle que le ciel et la mer
} 
nossa)

(Blaise Cendrars, Feuilles de route, 1924) (Tradução é

Sua discussão em sala de aula pode ser introduzida por perguntas como: o pronome "você" do título se refere a quem? Na primeira estrofe do poema o "você" se refere à mesma pessoa do "você" do título? Nesse poema o "você" pode ter diversas leituras, cabe ao professor estimular o aluno a expressar o que o poema lhe diz, como ele lhe fala, o que o poema lhe desperta enquanto objeto poético, a fim de motivar no aluno o prazer do texto. Pois ele se sentirá envolvido na atividade.

\section{Considerações Finais}

Em um momento em que se privilegia a comunicação, é importante que não nos esqueçamos da riqueza do texto literário, capaz de despertar a emoção do seu leitor e enriquecer não só um curso de língua estrangeira, por levantar múltiplas leituras, mas também o aluno. A literatura o coloca diante de outra visão do mundo, levando-o a refletir sobre seus valores. Abrir-se ao outro é descobrir a sua própria cultura. Uma das belezas do curso de língua estrangeira é colocar o aluno diante da diversidade cultural. Hoje o curso de língua estrangeira não tem mais o objetivo, como tinha a metodologia tradicional, de dar acesso a uma "cultura de prestígio". Sabemos que o aluno já tem a sua cultura de prestígio. Aprender um nova cultura é ter acesso a uma outra maneira de pensar, é conhecer um novo horizonte, a partir dele compará-lo com o seu, a fim de construir um mundo melhor, onde não haja culturas que subjugam as outras.

É preciso que o professor tenha em mente um projeto de leitura, antes de propor um texto literário e que neste projeto ele trabalhe as características do texto literário vistas neste artigo: polissemia, prazer e interculturalidade. Mesmo que o professor não encontre no método esse projeto, ele pode acrescentar algumas questões que aprofundem mais a entrada do aluno no texto e não fique sempre na superfície do mesmo.

Quand tu aimes il faut partir

Quitte ta femme quitte ton enfant

Quitte ton ami quitte ton amie

Quitte ton amante quitte ton amant

Quand tu aimes il faut partir 
Na conferência de abertura do XI Encontro Regional da Abralic, no dia 23 de julho de 2007, "O Ensino da Literatura Hoje" Leyla Perrone-Moisés afirma que nos últimos 20 anos houve um declínio do ensino literário não só no Brasil, mas também em Portugal e na França, pois a tendência do ensino foi substituir as áreas humanas por disciplinas mais técnicas. Entretanto ela finaliza a palestra respondendo a pergunta: Por que estudar literatura? Por que ensinar literatura é ensinar a ler, e aprender a ler é ter acesso à cultura. Sem leitura não há cultura.

\section{REFERÊNCIAS BIBLIOGRÁFICAS}

BESSE, H. "Poésie et expression”. Le Français dans le monde, nº103, 1974. . "Cultiver une identité plurielle". Le Français dans le monde, nº 254, 1993.

BARTHES, Roland. Essais critiques. Paris: Seuil,1964.

Le plaisir du texte. Paris : Seuil, 1973.

BRASIL, Ubiratan. "Brasileiro lê menos que há dois anos". O Estadão de São Paulo. São Paulo, 22 de fevereiro de 2010. Disponível em: http://www.estadao.com.br/estadaodehoje/20100222/not_imp514234,0.php. Acesso em 23 de julho de 2010.

CENDRARS, B. Feuilles de route. In: Au coeur du monde. Paris: Gallimard, 1924.

COLLÈS, L. Littérature comparée et reconnaissance interculturelle. Bruxelles: De Boeck, 1994.

COMPAGNON, M. “La Recherche à hauteur d'homme”. Le Magazine Littéraire. Paris. no.496, p.46-50, avril 2010.

CUQ, J.-P.; GRUCA, I. Cours de didactique du français langue étrangère et seconde. Grenoble : Presses universitaires de Grenoble, 2005.

DOLlEZ, C., PONS, S. Reflets Méthode de français 3. Paris: Hachette Livre, 2002, p. 16 e 17.

Reflets Méthode de français 3. Guide Pédagogique. Paris :

Hachette Livre, 2002, p. 22 a 24.

DURAS, M. India Song. Paris: Éditions Gallimard, 1973.

GIRARDET, J. Le Nouveau sans Frontière 4- Méthode de Français- Arts- CultureLittérature. Paris : CLE International, 1993, p. 188-189. 
et alii. Le Nouveau sans Frontière 4- Méthode de Français Livre du

Professeur. Paris : CLE International, 1993, p.107-109.

LITS, M. "Approche interculturelle et identité narrative". Etudes de Linguistique Appliquée, no. 93, 1994.

PENNAC, D. Comme un roman. Paris : Gallimard, 1992a.

. “N'ayez pas peur des livres”. L'Express, Paris, p.46-49,10 juillet,1992b.

PERRONE-MOISÉS, L. “O Ensino da Literatura Hoje”. São Paulo, 23 jul., 2007.

Palestra proferida no XI Encontro Regional da ABRALIC.

PIETRARÓIA, Cristina M. C. Percursos de leitura. São Paulo: Annablume, 1997.

SÉOUD, Amor. Pour une didactique de la littérature. Paris: Didier, 1997. 
ANEXO

ÉCRIT

\section{Passians \\ littéraires}

es années après la guerre, après les mariages, les enfants, les divorces, les livres, il était venu à Paris avec sa femme. Il lui avait téléphoné. C'est moi. Elle l'avait reconnu dès

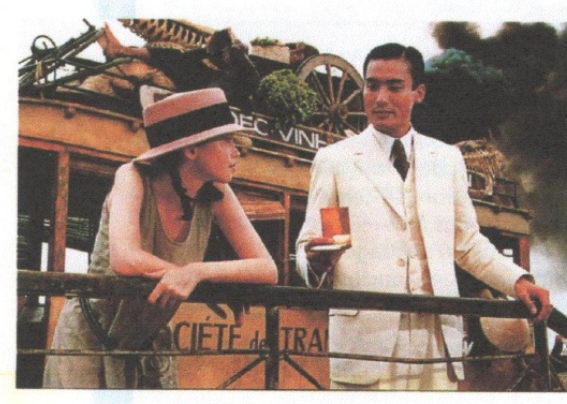

Première rencontre.

1 la voix. Il avait dit : Je voulais seulement entendre votre voix. Elle avait dit : C'est moi, bonjour. Il était intimidé, il avait peur comme avant. Sa voix tremblait tout à coup. Et avec le tremblement, tout à coup, elle avait retrouvé l'accent de la Chine. Il savait qu'elle avait commencé à écrire des livres, il l'avait su par la mère qu'il avait revue à Saigon. Et aussi pour le petit frère, qu'il avait été triste pour elle. Et puis il n'avait plus su quoi lui dire. Et puis il le lui avait dit. Il lui avait dit que c'était comme avant, qu'il l'aimait encore, qu'il ne pourrait jamais cesser de l'aimer, qu'il l'aimerait jusqu'à sa mort.
Monsieur de Nemours pensa expirer ${ }^{1}$ de 1 douleur en présence de celle qui lui parlait. Il la pria vingt fois de retourner parler à Madame de Clèves afin de faire en sorte qu'il la vit ; mais cette personne lui dit que Madame de Clèves lui avait non seulement défendu de lui aller redire aucune chose de sa part, mais même de lui rendre compte de leur conversation. Il fallut enfin que ce prince repartît, aussi accablé de douleur que le pouvait être un homme qui perdait toutes sortes d'espérances de revoir jamais une personne qu'il aimait d'une passion la plus violente, la plus naturelle et la mieux fondée qui ait jamais été. Néanmoins il ne se rebuta ${ }^{2}$ point encore, et il fit tout ce qu'il put imaginer de capable de la faire changer de dessein 3 . Enfin, des années entières s'étant passées, le temps et l'absence ralentirent sa douleur et éteignirent sa passion. Madame de Clèves vécut d'une sorte qui ne laissa pas d'apparence qu'elle pût jamais revenir.

Madame de La Fayette, La Princesse de Cleves. 1 Expirer (v.): mourir. 2 Se rebuter (v.) : se décourager. 3 Dessein (n. m.) : idée, but.
Marguerite Duras, L'Amant, Éd. de Minuit.

m'avait dit " tu n'écriras pas un livre sur moi ». Mais je n'ai pas écrit un livre sur lui, ni même sur moi. J'ai seulement rendu en mots - qu'il ne lira sans doute pas, qui ne lui sont pas destinés - ce que son existence, par elle seule, m'a apporté. Une sorte de don reversé.

Quand j'étais enfant, le luxe, c'était pour moi les manteaux de fourrure, les robes longues et les villas au bord de la mer. Plus tard, j'ai cru que c'était de mener une vie d'intellectuel. II me semble maintenant

Annie Ernaux

\section{Passion simple}

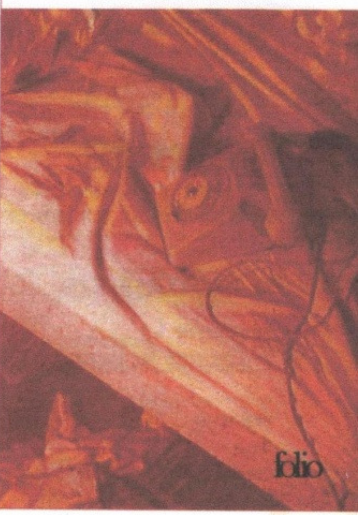
que c'est aussi de pouvoir vivre une passion pour un homme ou une femme.

Annie Ernaux, Passion simple, éd. Gallimard. 


\section{ÉCRII (1)}

Vous allez utiliser la matrice d'un récit littéraire pour relater une relation affective.

1 LISEZ

1 Lisez ces trois extraits de romans publiés en 1678, 1984 et 1991 et attribuez à chacun son année de parution.

2 Quel est leur thème commun ?

3 Quelle est la situation commune qu'ils exposent ?

\section{TEXTE 1}

4 Parmi les sentiments suivants, relevez ceux éprouvés par l'homme pendant son appel téléphonique.

Courage - gêne - curiosité - désespoir - désir timidité - peur - douleur - émotion -

déception - résignation.

Justifiez votre choix par des citations du texte.

5 En remettant ces sentiments dans I'ordre du texte, expliquez leur progression.

6 Relevez les phrases qui révèlent la passion de l'amant.

7 Relevez les phrases qui révèlent l'émotion de la narratrice.

8 Cette émotion est-elle due selon vous :

a à l'amour actuel ?

b au souvenir du passé ?

c à l'espoir d'une nouvelle aventure ?

\section{TEXTE 2}

9 Qui est le personnage principal ?

10 Les deux amants sont-ils en présence ?

11 Pourquoi n'a-t-on pas directement le point de vue de Madame de Clèves ?

12 Que rapporte-t-on de l'attitude de Madame de Clèves par rapport à l'amour exprimé ?

13 En vous aidant de la liste de sentiments de la question 4, identifiez les sentiments éprouvés par Monsieur de Nemours.

14 Sélectionnez la phrase qui qualifie la passion de Monsieur de Nemours pour Madame de Clèves.

\section{TEXTE}

15 Relevez les termes utilisés par l'auteur pour qualifier sa passion.

16 Pourquoi l'amant n'intervient-il paș ?

17 Quelle formule résume, selon le texte, le rôle de l'amant :

a avoir aimé cette femme?

b lui avoir donné du bonheur?

c lui avoir fait connaître la passion?

18 Parmi la liste de sentiments de la question 4

pouvez-vous en trouver un qui est exprimé dans ce texte?
TEXTES 1, 2 ET 3

19 Choisissez, parmi les adjectifs suivants, ceux qui semblent les plus appropriés pour caractériser le ton de chaque texte. Tragique - humoristique - détaché grandiloquent - attendri - agressif désespéré - indifférent.

\section{COMMENTEZ.}

Quel texte provoque en vous la plus forte émotion ? Pourquoi ?

\section{PRÉPAREZ VOTRE PRODUCTION.}

Relisez attentivement le texte 3 et observez sa structure.

1 Dans le premier paragraphe, on trouve :

a l'évocation de la dernière rencontre. Relevez le verbe qui la suggère ;

b l'excuse de la narratrice pour avoir écrit son livre. Relevez la conjonction et le verbe négatif qui le montrent

c l'explication. Relevez le verbe et son adverbe qui servent à la présenter.

z Dans le deuxième paragraphe, la narratrice relate une évolution.

a Relevez la proposition qui présente le passé lointain.

b Notez l'expression de temps qui marque le changement.

c Notez l'expression de temps qui désigne le temps présent.

d Notez les temps des verbes dans ces trois phrases et dites en quoi ils sont importants.

\section{4 ÉCRIVEZ}

Comme Annie Ernaux, vous avez connu une forte relation affective (réelle ou supposée) avec un(e) ami(e) qui n'est plus auprès de vous.

1 Relatez d'abord la dernière rencontre : IIIElle m'avait dit...

Mais..

Insistez sur le besoin d'en parler, de raconter l'importance de cette relation:

J'ai seulement.

Z Puis présentez l'évolution de ce lien à travers le temps:

Quand j'étais enfant.

Plus tard...

II me semble maintenant.. 


\title{
LA SCÈNE ET L'ÉCRAN
}

\section{LE MYSTÈRE DU PERSONNAGE}

\author{
" INDIA SONG ", TEXTE, THÉÂTRE ET FILM DE MARGUERITE DURAS
}

"India Song" est l'histoire d'un amour vécu aux Indes dans les années 30. Un homme, le Vice-consul de France à Lahore en disgrâce à Calcutta, est rejeté par ses pairs car il a tiré sur les lépreux de Lahore. Il crie son amour pour Anne-Marie Stretter, femme de l'ambassadeur de France, qui a pour amant Michaël Richardson. Parallelement se déroule une autre histoire : celle d'une mendiante venue à pied du Laos jusqu'à Calcutta.

Les histoires ne sont pas racontées au sens classique du terme. Elles sont évoquées par des voix (off)

qui se souviennent, par des images, par des bribes de conversation entre les témoins de ses amours et par quelques dialogues entre les personnages.

Voici une séquence du début du film. Des formes, des silhouettes, des voix et des bruits ont peu à peu émergé de l'écran noir. Le décor est celui de l'ambassade de France, intérieur et parc. Une femme habillée de noir danse avec un homme en noir. Près d'eux un autre bomme en noir.

La lumière revient peu à peu.

La pluie, le bruit, très fort pendant plusieurs secondes.

Il diminue. Les cris isolés et les rires percent, plus précis, le bruit de la pluie.

La lumière revient toujours.

Tout à coup, cris plus précis, plus près, de femme. Rires de la même femme.

volx 1

Quelqu'un crie... une femme...

voIx 2

Quoi ?

VOIX 1

Des mots sans suite.

Elle rit.

volx 2

Une mendiante.

vorx 1

Temps.

Folle?

VOIx 2

C'est ça...

Dans les allées du parc, soleil d'après la pluie. Soleil mouvant. Taches de lumière grise, pâle.

Cris et rires de la mendiante toujours.

VoIx 1

Ah oui... je me souviens. Elle se tient au bord des fleuves... elle vient de Birmanie... ?

vox 2

Oui.

Tandis que les voix parlent de la mendiante les trois personnes bougent, quittent la pièce par des portes latérales. volx 2

Elle n'est pas indienne.

Elle vient de Savannakhet.

Née là-bas.

VOIX 1

Ah oui... oui...

Un jour... il y a dix ans qu'elle marche, un jour, devant elle, le Gange... ?

Oui.

Elle reste.

volx 2

volx 1

C'est ça...

Les trois personnes ont disparu. L'endroit est vide. Discours au loin, comme crié, dans une langue douce : le laotien.

VoIx 1 (Temps)

Douze enfants morts tandis qu'elle marche vers le Bengale... ?

volx 2

Oui. Elle les laisse. Les vend. Les oublie. (Temps.) Vers le Bengale devient stérile.

IUne réception à l'ambassade de France. Bribes de conversations des invités.]

Michael Richardson se lève, il fait quelques pas vers la réception, la regarde d'assez loin, puis il se retourne : voir le Vice-consul dans le parc.

Alors les femmes le voient aussi et reculent d'un pas.

Des femmes parlent (bas):

- Regardez... Michael Richardson...

188 - La tentation de l'IrrationNet 


\section{LA SCĖNE ET L'ÉCRAN}

Temps.
- Ah oui... Il ne vient pas aux réceptions...?

- Jamais, à la fin seulement, vers le milieu de la nuit. Ils restent à quelques intimes.

Temps.

- Quelle histoire... quel amour... On dit qu'il a tout quitté pour la suivre...

- Tout. Il était fiancé. Tout. En une nuit...

$$
\text { Silence. }
$$

Le Vice-consul regarde la réception. Michaël Richardson, de nouveau, le regarde. Le Vice-consul paraît très absorbé, ne le remarque pas.

Des hommes parlent :

- La nuit il tirait de son balcon.

- Oui. Il criait aussi. À moitié

nu.

-Quoi?

- Des mots sans suite. Il riait. Temps.

- Aucune femme, à Lahore, ne l'aurait connu d'assez près qui pourrait dire un peu...?

- Aucune. Jamais.

- Comment est-ce possible?

- Dans sa résidence, personne n'est jamais allé, dans sa résidence de Lahore..

- C'est terrifiant... Cette abstinence... Terrible...

Silence.

- Vous avez entendu ? L'Ambassadeur a dit au Jeune Attaché : "Les gens s'écartent de lui, je sais... il fait peur... mais vous m'obligeriez si vous alliez lui parler un peu."

Temps.

- Sur le milieu que sait-on? sur l'enfance?

- Son père, petit banquier à Neuilly. Enfant unique. Sa mère aurait quitté le père. Nombreux renvois pour mauvaise conduite. Études brillantes mais après le secondaire... c'est tout...

- On ne sait rien en somme...

- Rien.

Temps.

- Est-ce qu'il n'y aurait pas en chacun de nous... comment dire? une chance sur mille d'être comme lui à... enfin... (Arrêt) je pose la question.. c'est tout...

Pas de réponse. Silence.

Marguerite Duras, India Song, Gallimard, 1973.

\section{LE RECIT POLYPHONIQUE}

- Dans ces deux extraits relevez du Vice-consul et de Michael les éléments (indications scé- Richardson,

niques ou paroles) qui se rap- - à d'autres domaines. De quels portent :

- à l'histoire de la mendiante, la fonction de ces eléments?

Informations sur l'histoire Autres éléments

- Retour de la lumieres peronges - Retour de la lumière - persennages
et décor sortent progressivement du passé et de Poubli.

- Ambiances sonores (pluie, cris, rires) évocation sonore de l'Inde.

- Cris de la mendiante (douleur, folie ?)

- Rassemblez ces informations en résumant ce que vous avez appris :

- sur l'histoire,

- sur le décor et l'atmosphère.

L'ÉCRITURE MAGIQUE

- Sélectionnez dans ce texte

un passage descriprif, un passage narratif, un dialogue. Comparez ces passages avec leurs correspondants dans la littérature classique. Dégager la spécificité du récit, de la description et du dialogue chez Marguerite Duras.

- Montrez que l'écriture de Marguerite Duras tient à la fois du roman, du poème et du film.

- Les formules suivantes vous paraissent-elles caractériser le contenu et la forme de ce film? - juxtaposition d'informations

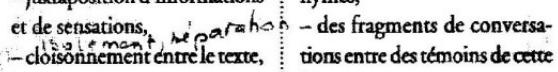

llimage et les personnages, histoire.
- décalage des points de vuesur les personnages,

- écriture musicale,

- fragments de souvenirs,

- présence mystérieuse et fantômatique des personnages.

LES THEMES

- Répertotiez les thèmes qui affleurent tout au long de ce texte : la solitude, la folie, etc. - Définissez la tonaliuéc créée par la succession et le retour de ces thèmes.

\section{CRÉATTVITE}

- Racontez une histoire poétique (par exemple celle de $\mathrm{Ge}$. rard de Nerval, p. 48 ou celle de Julien Gracq, p. 17) en utilisant lune des deux techniques employées par Marguerite

Duras :

LA tentation de L'IrRationnel • 189
- une polyphonie de voix ano 